\title{
Design of an Automated White Board Profiler
}

\author{
Md. Tanzim Hasan', Shahin Parvez ${ }^{1}$, Shaylesh Roy ${ }^{1}$, Md. Abdullah Sakib², and K. M. Khalidur Rahman² \\ ${ }^{1}$ Bangladesh Army University of Science and Technology/School of Mechanical Engineering, Saidpur-5310, Bangladesh \\ ${ }^{2}$ Bangladesh Army University of Science and Technology/School of Computer and Electrical Engineering, Saidpur-5310, Bangladesh
}

\begin{abstract}
This paper presents the design for an automated and modernized white board profiler. The design objectives were to: (a) Introducing the concept for a new method of white board cleaning. (b) Getting rid of time consuming old methods. (c) Introducing the design with a CAD model with circuit analysis. Proving that it is time and labor efficient while being cost efficient to do it by using electricity and mechanical body Also, enhancing the accessibility of the user and increasing efficiency in terms of use. This work is expected to contribute to the overall knowledge of machine design and white board cleaning automation in specific.
\end{abstract}

\section{Introduction}

White board is an important aspect of any modern classroom. Teachers, Students all the persons present in a classroom looks up to it to acquire and give knowledge by using it to share information. It's an important part of a classroom. A teacher may give lecture orally. But when it's written or presented on the white board it becomes clear. And it may become clearer when it's graphical as a teacher may draw figures on it to make students understand properly and efficiently. It doesn't need much maintenance. All it needs is a marker to write and a cloth or duster to clean. Although it doesn't take much time to clean it, but it's an orthodox way of cleaning to do it by hand. As, it takes more time and strength to do so, it's easy to clean only one line. But when the board is full it's difficult and tiring to do so, That's why this paper aims to get rid of that way of cleaning and introduce a new and modernized automated way to clean the white board with efficiency and perfection in a much less time. So, it can be ready for the next class or lecture for the students and teachers altogether. It will help in all around class work and save time evidently. It will also get rid of strength consuming and pain elevating wiping that may be done by hand.

\section{Conceptual design}

The white board profiler was designed as a whole setup and was divided into sections for clear understanding and view. Firstly, we can see the whole setup. The body is envisioned to be made of Synthetic industrial Plastics, [1]. There are rail and gear pathways on top and bottom of the white board. With two obstacles on each sides that acts as a double as a marker holder. And finally the cleaner part that is situated on the rail and gear pathaways.
It's adjacent and will rub against the white board surface. The whole setup is designed to be wire-less and remote control as a secondary option but it's primary function is to be wired and switched.

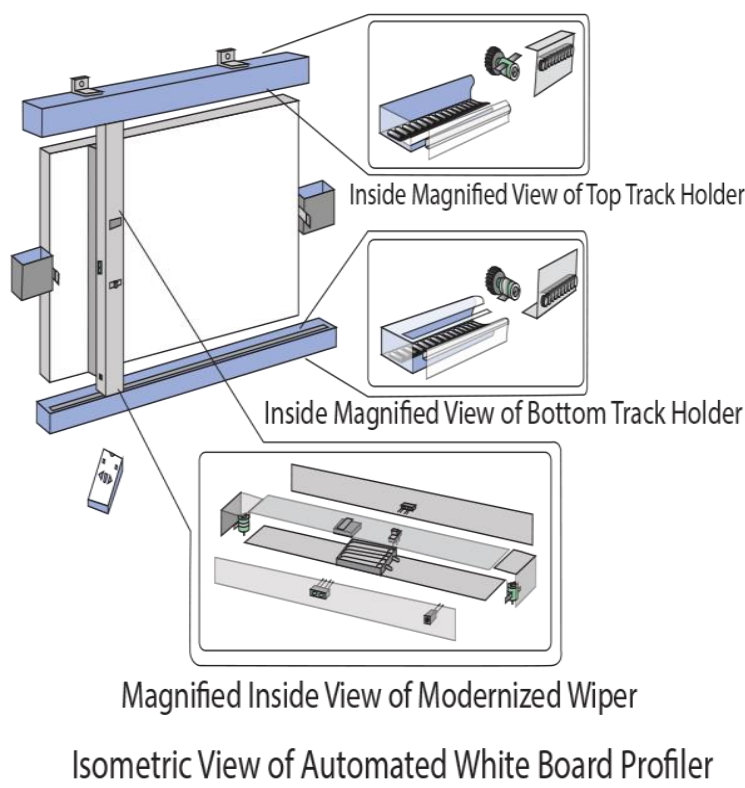

Figure 1. Concept design of the whole setup.

As we can see from Fig. 1, the whole setup is done on wall. The upper and bottom pathways is set up with hinges for support. The obstacles are set up with screw. The modernized wiper part rolls on the pathways with mainly gear and also support wheels for additional support and mobility with less friction.

\subsection{Wiper track}


The wiper mainly runs on a track path made by gear and wheels. The Track has two parts are: 1. Top Track Holder. 2. Bottom Track Holder. Both of them are mirror of each other and has the same principle.

\section{Top Track Holder}

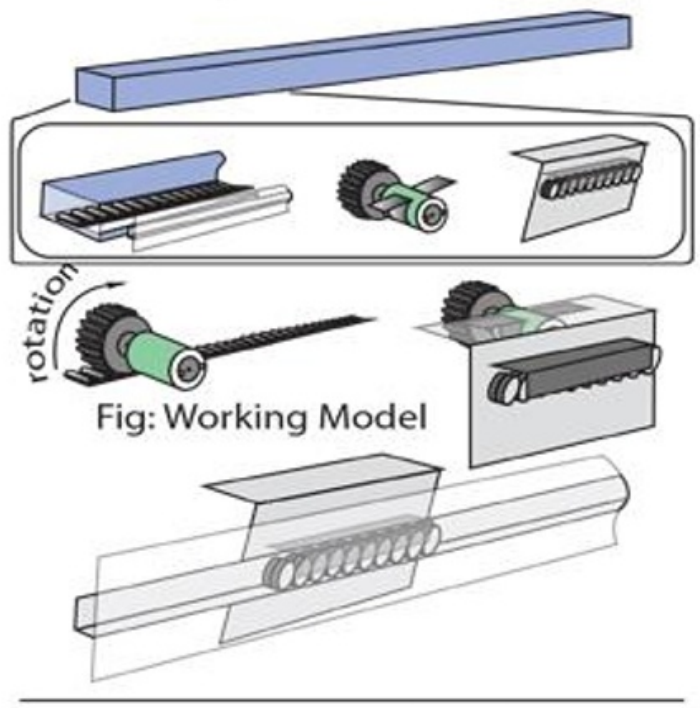

\section{Bottom Track Holder}
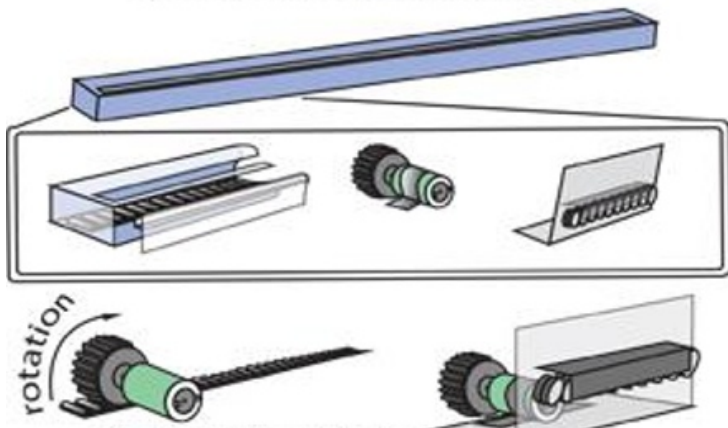

Fig: Working Model

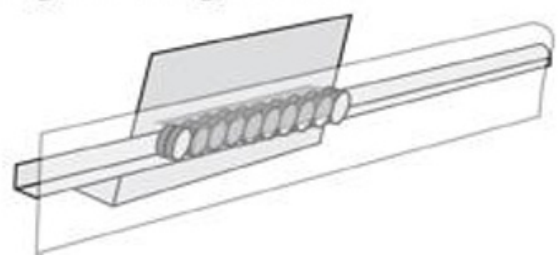

Figure 2. Wiper track.

As we can see from Fig. 2, the track pathways are made with gear and supported wheels. The gears have motor and clam attached with them and it is fixed with the wiper as it moves the wiper. The wiper also has added support wheels which helps in displacement and mobility with also reducing it's friction when needed. The track also has a path for these support wheels. Both the upper and bottom part of the track is distanced from the white board, And has the same mirrored function overall.

\subsection{Modernized wiper}

Ultimately we come to the main part of this setup that is the modernized wiper. The wiper runs on motors mainly the two that is discussed above. The motor has gears and support wheels are attached to the wiper body to make it more frictionless and mobile. The duster part that cleanes the board is replace-able by simple lock for replacing the duster if and when needed. There are two motors in the model that runs on battery. It also has a remote control receiver and switch inside of it. As, it can be made both wireless or wired, As the controllers are Adaptive and Infrared is used, [2, 3]. It also has a charging port. For charging the re-chargable battery that will be used in the wiper.

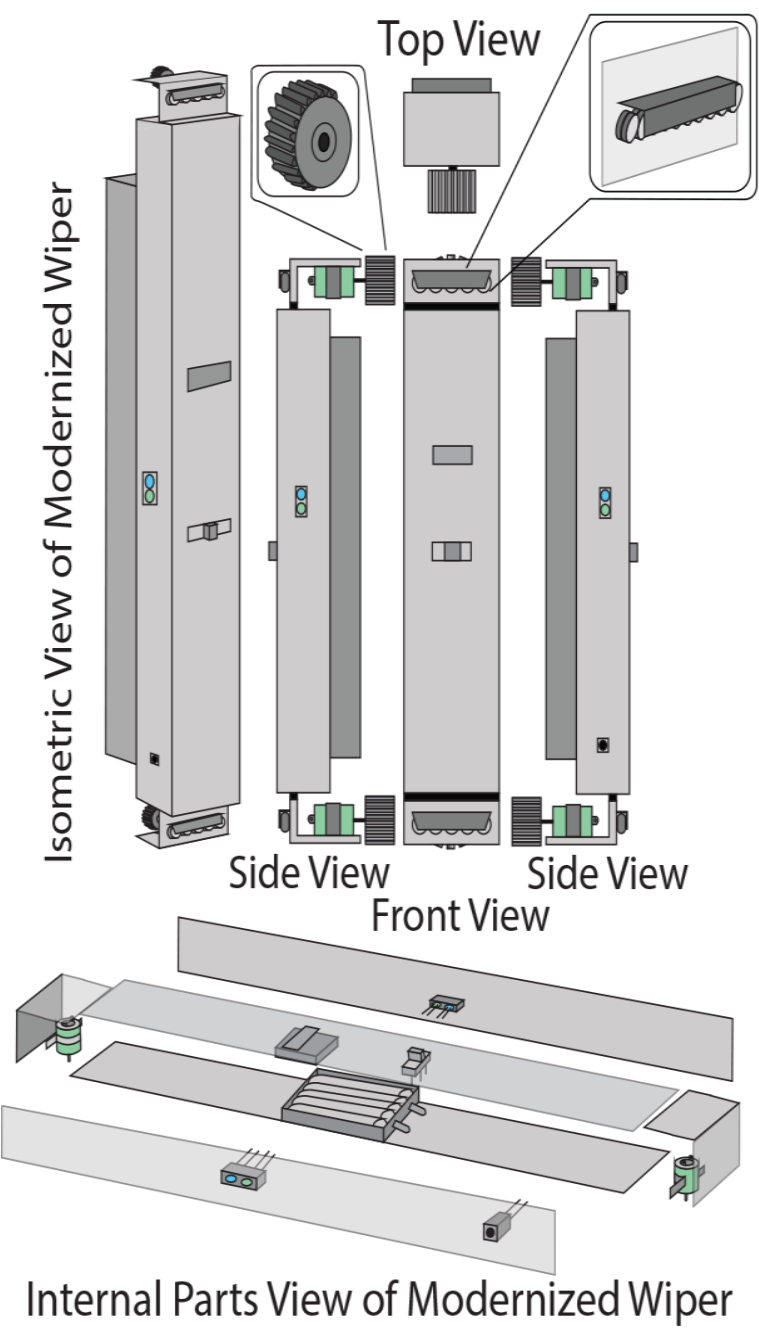

Figure 3. Modernized wiper.

One other important thing that the wiper has is, the obstacle sensor. The obstacle sensor is made to sense the obstacle that was previously discussed and shown in Fig. 1 . The sensor senses the obstacle and reverses when it is close to it. All of it is shown in Fig 3. That way it can wipe clean both sides in much less time with more efficiency. All the electrical parts are assembled in a circuit that will be discussed later in the paper.

\section{CAD model}


The whole setup and it's parts were made into CAD with the help of SolidWorks 2014C software for more realistic approach and design with it's properties and formation. The design will help in understanding how the the model would look in real life.

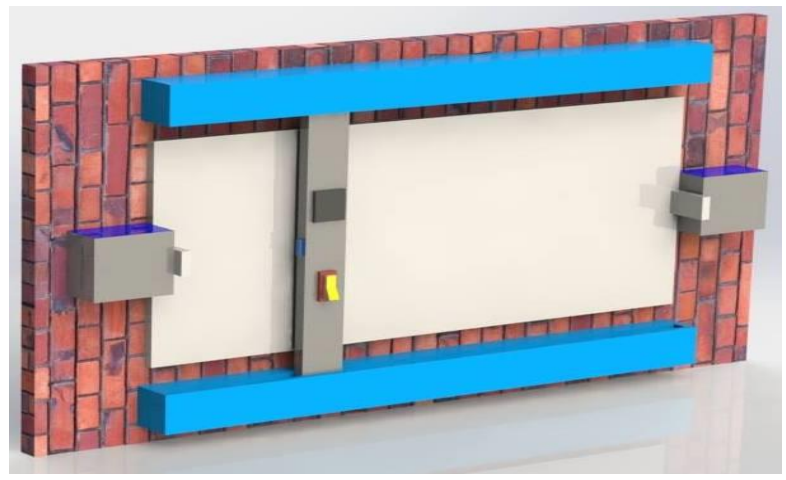

Figure 4. CAD model of the full setup.
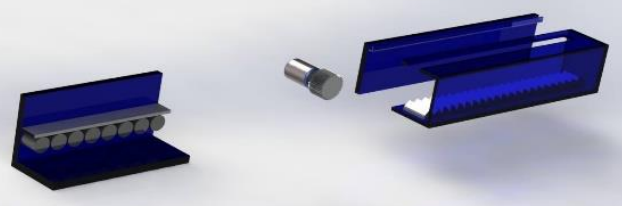

Figure 5. CAD model of the top track holder.

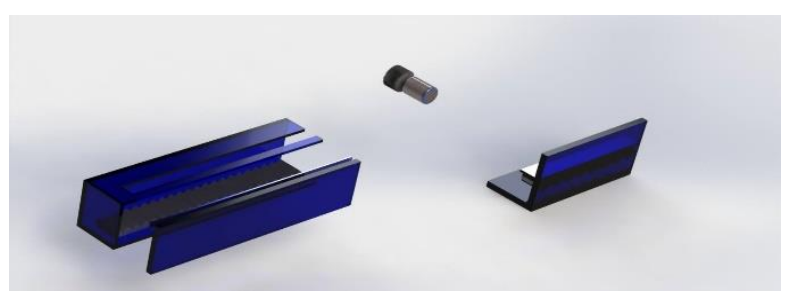

Figure 6. CAD model of the bottom track holder.

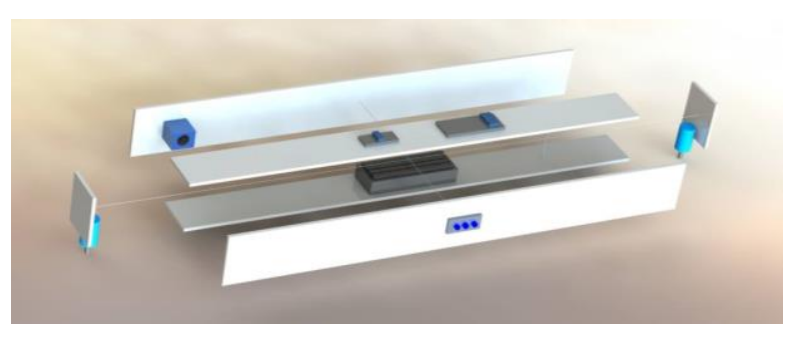

Figure 7. CAD model of the modernized wiper.

From Fig. 4 to Fig. 7, These CAD models shows the real life like design of the white board profiler and it's different parts. It is inspired by model based system engineering, [4, 5]. It will help in understanding the design properly and effectively.

\section{Circuit design}

As the model is run on electricity. May it be ac or dc as the design was made to provide both. That's why a circuit analysis was made to fully understand the circuit works and electrical works. The circuit was made with help of programmable circuit primarily Arduino@ . Which helps the censor to find obstacle and report it back to the motors for changing their direction in the opposite side to get the board back.

The circuit was designed with the help of Proteus Design Suite $\subset$. The fig. of the circuit is provided below.

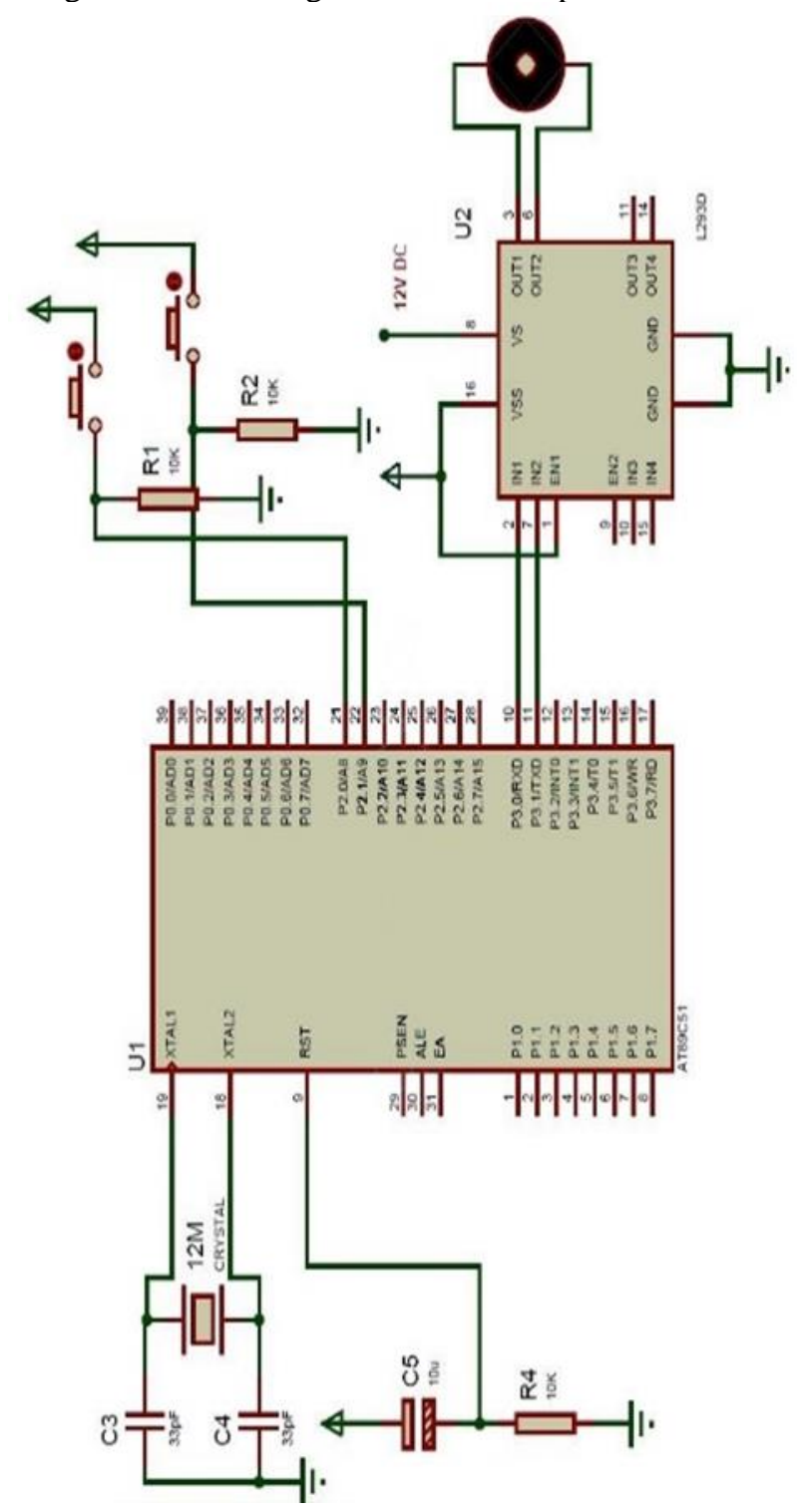

Figure 8. PCB circuit analysis.

As shown in Fig. 8, this circuit analysis describes the use of PCB and its effects on the motor. This circuit is done for the modernized wiper. It helps in turning the wiper back on the track once it has sensed the obstacle by obstacle sensor.

The circuit is an important part of the wiper. It's mainly the backbone that helps in moving the modernized wiper properly. The circuit is mainly to move the motor that holds the gear and sensing the obstacles and reversing the motors. It's an important operation for the modernized wiper. The programming code for the Arduino is also provided below. 


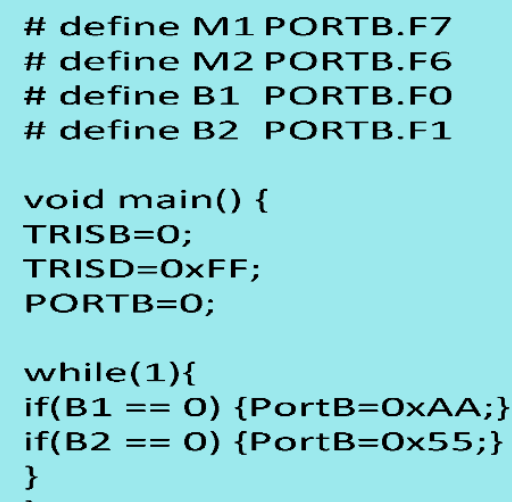

Figure 9. Programming code for Arduino.

As shown in Fig. 9, This is the programming code that is put into the Arduino, That oversees the whole operation and controls the PCB. This type of programming is seen in many automated machines. Such as, An Automated Waste Bin Monitor, [6].

\subsection{Circuit analysis result}

An analysis was made to understand the voltage, current, torque and other properties that is seen in the circuit and the modernized wiper. A table is provided below for proper understanding.

Table 1. Result Analysis.

\begin{tabular}{|c|c|c|c|c|c|}
\hline Input & $\begin{array}{l}\text { Voltage } \\
\text { (V) }\end{array}$ & $\begin{array}{l}\text { Current } \\
\text { (A) }\end{array}$ & $\begin{array}{l}\text { Motor } \\
\text { Output } \\
\text { (Watt) }\end{array}$ & $\begin{array}{l}\text { Require } \\
\text { d Power } \\
\text { (Watt) }\end{array}$ & $\begin{array}{l}\text { System } \\
\text { Weight } \\
(\mathrm{kg})\end{array}$ \\
\hline 16 & 15.2 & 2.54 & 38.608 & \multirow{4}{*}{$\begin{array}{l}2.99 \\
\text { (Total } \\
\text { Force) }\end{array}$} & \multirow{4}{*}{$\approx 2.00$} \\
\hline 12 & 11.4 & 1.9 & 21.66 & & \\
\hline 8 & 7.62 & 1.27 & 9.6774 & & \\
\hline 6 & 5.71 & 0.95 & 5.4245 & & \\
\hline
\end{tabular}

1. Brush Bar $=450$ gm including brush.

2. Battery $=34 \times 5 \mathrm{gm}$.

3. Drag Force $=1380 \mathrm{gm}$.

4. Approximate Torque 6.52 g.cm.

5. Total Effective Length $240 \mathrm{~cm}$.

6. Total working time $5 \mathrm{sec}$. Speed $=48 \mathrm{~cm} / \mathrm{sec}$ (The power required for this motor was driven by comparing to a large motor's reading which was $1000 \mathrm{w} 48 \mathrm{~V}$ DC).

We can see from the results that the final speed of the board will be $48 \mathrm{~cm} / \mathrm{sec}$. The drag force would be 1380 gm. The Approximate Torque 6.52 g.cm. It will be more than enough to clean the board in and under 5 seconds. The device will clean the board in much less time and with efficiency than done by human hands.

\section{Cost analysis}

Currently the conventional methods of cleaning the whiteboard includes many ways which includes chemicals, cleaning cloth, dusters, wipes etc. They are relatively cheap costing around $\$ 5.96$ to $\$ 212.00$. But all of them require handwork and labor. Which eventually is time consuming and painful.

This setup can be made in any industry or at home. The production cost is very low and cost efficient, eventually cheaper than conventional methods. It can be assembled by hand. The whole setup will cost around $\$ 30$. And will be very time saving while being used. Conventional cleaning requires the use of hand which takes much time. But this automatic setup will do it under 5 seconds.

\section{Conclusion}

This paper indicates the development and conceptual design for a new technological achievment in the field of classroom and technology. The technology and electrical aspects that are used in in the design for this device is relatively easy and properly used in modern technological areas. This will help in time saving as well as efficiency in modern classrooms. And will help in saving time for the teacher and students alike. Giving more time to improve in many areas and study as well as work. Also having room to improve itself in many areas. Though in this paper the development work is for only one board but it can be developed for more board and more development gradually.

\section{Acknowledgement}

This work has been supported in part by the grant provided by the Research Fund of Bangladesh Army University of Science and Technology, Saidpur, Rangpur, Bangladesh.

\section{References}

1. G. O. Young, "Synthetic structure of industrial plastics," in Plastics, 2nd ed. vol. 3, pp. 15-64. (1964).

2. S. P. Bingulac, "On the compatibility of adaptive controllers," in Proc. 4th Annu. Allerton Conf. Circuits and Systems Theory, pp. 8-16, (1994).

3. J. U. Duncombe, "Infrared navigation-Part I: An assessment of feasibility," IEEE Trans. Electron Devices, vol. ED-11, pp. 34-39, Jan. (1959).

4. B. P. Douglass, "Chapter 1 - What Is Model-Based Systems Engineering?” in Agile Systems Engineering, Boston: Morgan Kaufmann, pp. 1-39, (2016).

5. N. Van, K. Gadeyne, and M. Witters, "Model-based systems engineering of discrete production lines using SysML: An experience report," Procedia CIRP, vol. 60, pp. 157-162, (2017).

6. Md Ahad Bin Alam, International Journal of Advanced Research in Electrical, Electronics and Instrumentation Engineering. Automated Waste Bin Monitor. 